\title{
A COMPARISON OF THE POTENCY OF TRIMEDOXIME AND OTHER CURRENTLY AVAILABLE OXIMES TO REACTIVATE TABUN-INHIBITED ACETYLCHOLINESTERASE AND ELIMINATE ACUTE TOXIC EFFECTS OF TABUN
}

\author{
Jiř́i Kassa, Kamil Kuča, Jiří Cabal
}

\author{
Department of Toxicology, Faculty of Military Health Sciences, Trebešská 1575, 50001 Hradec Králové, Czech Republic \\ e-mail:kassa@pmfhk.cz
}

Received: June 10, 2005; Accepted: September 25, 2005

Key words: Tabun/Acetylcholinesterase/Trimedoxime/Pralidoxime/Obidoxime/HI-6/Rats/Mice

Tabun ( $O$-ethyl- $N, N$-dimethyl phosphoramidocyanidate) belongs to highly toxic organophosphorus compounds misused as chemical warfare agents for military as well as terroristic purposes. It differs from other highly toxic organophosphates by its chemical structure and by the fact that tabun-inhibited acetylcholinesterase is extraordinarily difficult to reactivate.

The potency of trimedoxime and other commonly used oximes (pralidoxime, obidoxime, the oxime HI-6) to reactivate tabun-inhibited acetylcholinesterase and to eliminate tabun-induced acute effects was evaluated using in vitro and in vivo methods. In vitro calculated kinetic parameters of reactivation of tabun-inhibited acetylcholinesterase from rat brain homogenate and in vivo determined percentage of reactivation of tabun-inhibited blood and tissue acetylcholinesterase in poisoned rats show that trimedoxime seems to be the most efficacious reactivator in the case of tabun poisonings. Trimedoxime was also found to be the most efficacious oxime in the elimination of acute lethal toxic effecs in tabunpoisoned rats and mice. The oxime HI-6, so efficacious against soman, does not seem to be sufficiently effective oxime to reactivate tabun-inhibited acetylcholinesterase and to counteract acute lethal effects of tabun.

\section{INTRODUCTION}

The current standard treatment for poisoning with highly toxic organosphosphorus compounds called nerve agents usually consists of the combined administration of anticholinergic drugs (preferably atropine) and oximes (preferably pralidoxime or obidoxime). Anticholinergic drugs block effects of overstimulation by accumulated acetylcholine at muscarinic receptor sites while oximes, compounds with nucleophilic activity, repair biochemical lesions by dephosphonylating nerve agent-inhibited acetylcholinesterase (AChE, EC 3.1.1.7) and restoring its activity ${ }^{1}$.

Tabun is probably one of the most dangerous compounds among nerve agents, since its deleterious effects are extraordinarily difficult to counteract because of the existence of a lone electron pair located on an amidic group that makes the nucleophilic attack almost impossible ${ }^{2,3}$. While anticholinergic drugs such as atropine are able to counteract the effects of tabun at peripheral cholinergic receptors ${ }^{4}$, commonly used reactivators of phosphonylated AChE based on monopyridinium (e.g. pralidoxime) and bispyridinium oximes (e.g. obidoxime, methoxime) are not able to counteract the toxic effects of tabun because of very little reactivating efficacy ${ }^{5}$. In addition, the reactivating efficacy of the oxime HI-6, so efficacious against toxic effects of $\operatorname{soman}^{6,7}$, is not so high for tabun-inhibited $\mathrm{AChE}^{8,9}$. Thus, the replacement of commonly used oximes (pralidoxime, obidoxime) as well as $\mathrm{H}$ oximes (the oxime HI-6) with a more effective oxime has been a long-standing goal for the treatment of tabun poisoning. One of the candidate for this replacement seems to be another bispyridinium oxime, trimedoxime, that does not belong to the commonly used oximes for the treatment of acute poisoning with nerve agents.

There are many ways of evaluating therapeutic effects of antidotes against nerve agents. In the case of oximes, the evaluation of their reactivation ability both in vitro and in vivo is very important because their reactivating potency underlies their beneficial effects. In vitro assessment of reactivating efficacy of oximes is usually followed by the evaluation of their reactivating efficacy in vivo and their therapeutic efficacy against lethal nerve agent poisoning ${ }^{5}$.

The aim of this study was to compare the reactivating and therapeutic efficacy of trimedoxime with currently available oximes (pralidoxime,. obidoxime, the oxime HI6) against tabun using both in vitro and in vivo methods.

\section{MATERIAL AND METHODS}

Male albino Wistar rats weighing 180-220 g and male NMRI mice weighing 20-22 g were purchased from Konárovice, Czech Republic. They were kept in an airconditioned room with the light from 07:00 to 19:00 h 
and were allowed access to standard food and tap water ad libitum. The rats as well as mice were divided into groups of eight animals. Handling of the experimental animals was done under the supervision of the Ethics Committee of the Faculty of Military Health Sciences, Czech Republic.

Tabun was obtained from the Technical Institute in Brno (Czech Republic) and was $89 \%$ pure. The monopyridinium and bispyridinium oximes (pralidoxime, obidoxime, trimedoxime, the oxime HI-6) were earlier synthesized at the Department of Toxicology of the Faculty of Military Health Sciences (Czech Republic). Their purities were analysed using a HPLC technique. All other drugs and chemicals of analytical grade were obtained commercially and used without further purification. All substances were administered intramuscularly (i.m.) at a volume of $1 \mathrm{ml} / \mathrm{kg}$ body weight (b.w.).

In vitro testing of oximes involved a standard collection of experimental procedures ${ }^{10}$. The reactivating efficacy of oximes was evaluated in $10 \%$ rat brain homogenate that was incubated with tabun for 30 minutes and then, the tested oxime was added for 10 minutes. The activity of brain AChE was measured by potentiostatic method with the help of automatic titrator RTS 822 (Radiometer, Denmark). The data about initial rate of enzyme reaction with substrate made possible the calculation of the dissociation constant of enzyme-reactivator complex $\left(K_{\mathrm{dis}}\right)$, the dissociation constant of enzyme-inhibitor-reactivator complex $\left(K_{\mathrm{R}}\right)$ and the first-order rate constant $\left(k_{\mathrm{R}}\right)$. The ability of oximes to reactivate tabun-inhibited AChE was calculated as the percentage of increasing in the activity of reactivated enzyme in the reaction mixture ${ }^{11}$.

The ability of oximes to reactivate tabun-inhibited $\mathrm{AChE}$ in vivo was determined as follows. To evaluate the reactivating efficacy of the oximes, the rats were injected i.m. with either atropine $(21 \mathrm{mg} / \mathrm{kg})$ alone or atropine $(21 \mathrm{mg} / \mathrm{kg}$ ) in combination with one of the oximes studied in equimolar dose $(100 \mu \mathrm{mol} / \mathrm{kg}) 5 \mathrm{~min}$ before the rats

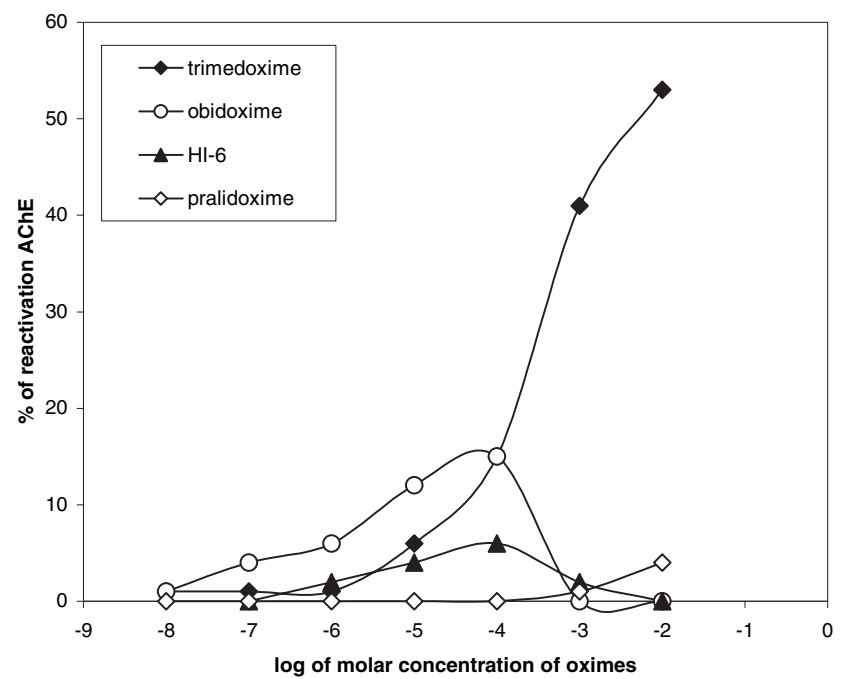

Fig. 1. Reactivation-concentration relationships of oximes to tabun-inhibited AChE - semilogarithmic transformation. received tabun i.m. at a dose of $130 \mu \mathrm{g} / \mathrm{kg}\left(\mathrm{LD}_{50}\right)$. The prophylactic administration of antidotes was used because this procedure is suitable for a mechanistic study that compares the reactivating efficacy of various oximes ${ }^{12}$. The rats were decapitated and exsanguinated to obtain the blood 30 min following tabun poisoning. The diaphragm and the brain were removed and homogenized in distilled water to determine AChE activity by a spectrophotometric method $^{13}$. The reactivation rate was calculated using the AChE activity values: $1-$ [(oxime + atropine $)-($ saline $) /$ (atropine control) - (saline) $) \times 100\left(\right.$ ref. $\left.^{12}\right)$. The AChE activity was expressed as $\mu \mathrm{kat} / \mathrm{kg}$ or $\mathrm{L}$ ( $\mu \mathrm{mol}$ substrate hydrolyzed/kg wet tissue or L blood/s).

The therapeutic efficacy of oximes against supralethal poisoning with tabun in rats was determined by the evaluation of the $\mathrm{ED}_{50}$ values and their $95 \%$ confidence limit using probit-logarithmical analysis of death occurring within $24 \mathrm{~h}$ following tabun poisoning in at least four groups of eight animals ${ }^{14}$. In these experiments, the oximes were injected i.m. in the same solution as atropine (21 mg/kg) $5 \mathrm{~min}$ before i.m. administration of tabun at the supralethal dose $\left(3 \times \mathrm{LD}_{50}\right)$. The acute toxicity of all oximes tested ( $\mathrm{LD}_{50}$ values) was also determined by probit-logarithmical analysis ${ }^{14}$. Finally, the safety of oxime treatment with the efficacious doses was determined by the calculation of safety ratio $\left(\mathrm{LD}_{50} / \mathrm{ED}_{50}\right.$ value, $\left.\mathrm{SR}\right)$.

The therapeutic efficacy of oximes against supralethal poisoning with tabun in mice was determined by the assessment of the $\mathrm{LD}_{50}$ values and their $95 \%$ confidence limit using probit-logarithmical analysis of death occurring within $24 \mathrm{~h}$ after i.m. administration of tabun at five different doses with eight mice per dose ${ }^{14}$. Tabun-poisoned mice were treated i.m. with one of tested oximes at equieffective doses $\left(2 \% \mathrm{LD}_{50}\right)$ in combination with atropine $(21 \mathrm{mg} / \mathrm{kg}$ ) one min after i.m. challenge of tabun. The efficacy of tested oximes in combination with atropine was expressed as protective ratio $\left(\mathrm{LD}_{50}\right.$ value of tabun in protected mice/ $\mathrm{LD}_{50}$ value of tabun in unprotected mice).

Statistical significance was determined by the use of Student's t-test and differences were considered significant when $\mathrm{p}<0.05$. Statistical evaluation was determined with the relevant computer programs ${ }^{14}$.

Table 1. Kinetic parameters of the reactivation of tabun-inhibited $\mathrm{AChE}$ in rat brain homogenate in vitro

\begin{tabular}{|l|c|c|c|}
\hline OXIME & $k_{\mathrm{R}}(\min -1)$ & $K_{\mathrm{R}}(\mu \mathrm{M})$ & $K_{\text {dis }}(\mu \mathrm{M})$ \\
\hline Pralidoxime & 0.006 & 575 & 210 \\
\hline Obidoxime & 0.020 & 3.2 & 280 \\
\hline HI-6 & 0.007 & 6.3 & 24 \\
\hline & 0.079 & 46 & 21000 \\
\hline
\end{tabular}

$K_{\text {dis }}$, dissociation constant of the enzyme-reactivator complex; $K_{\mathrm{R}}$, dissociation constant of inhibited enzymereactivator complex; $k_{\mathrm{R}}$, the first-order rate constant of reactivation. 

acetylcholinesterase and eliminate acute toxic effects of tabun

Table 2. Rate of reactivation of tabun-inhibited AChE by oximes in rat blood, diaphragm and brain in vivo

\begin{tabular}{|c|c|c|c|}
\hline \multirow{2}{*}{ TREATMENT } & \multicolumn{3}{|c|}{ AChE activity $(\mu \mathrm{kat} / \mathrm{L}$ or $\mu \mathrm{kat} / \mathrm{kg})$} \\
\cline { 2 - 4 } & Blood & Diaphragm & $24.9 \pm 4.9^{\mathrm{a}}$ \\
\hline Atropine & $1.18 \pm 0.38^{\mathrm{a}}$ & $5.71 \pm 2.62^{\mathrm{a}}$ & $31.7 \pm 10.8$ \\
\hline Atropine + pralidoxime & $1.38 \pm 0.32$ & $11.48 \pm 4.19$ & $(1.9)$ \\
\hline \% reactivation $)$ & $(1.8)$ & $\left.118.6^{*}\right)$ & $38.8 \pm 7.2$ \\
\hline Atropine + obidoxime & $3.98 \pm 0.63$ & $\left(32.4^{* * *}\right)$ & $24.9 \pm 4.7$ \\
$(\%$ reactivation) & $\left(25.2^{* * *}\right)$ & $5.72 \pm 2.10$ & $(0)$ \\
\hline Atropine + HI-6 & $1.50 \pm 0.43$ & $(0)$ & $65.7 \pm 11.2$ \\
(\% reactivation) & $(2.9)$ & $15.41 \pm 2.47$ & $\left(11.5^{* * *}\right)$ \\
\hline Atropine + trimedoxime & $3.35 \pm 0.81$ & $\left(31.4^{* * *}\right)$ & \\
(\% reactivation) & $\left(19.5^{* * *}\right)$ & & \\
\hline
\end{tabular}

${ }^{a}$ Means \pm S.E.M., $N=8$. The untreated control value for rat blood AChE activity was 19.5 ( $\mu$ kat/L), for diaphragm AChE activity $24.0 \mu \mathrm{kat} / \mathrm{kg}$ and for brain AChE activity $293.3 \mu \mathrm{kat} / \mathrm{kg}$. ${ }^{\mathrm{b}}$ Percent reactivation was determined using the AChE activity values: 1 - [(oxime + atropine $)-($ saline $) /($ atropine control $)-($ saline $)] \times 100$.

* Significantly different from the atropine group at a level of $p<0.05\left({ }^{* * *} \mathrm{p}<0.001\right)$ as determined by the Student's test.

\section{RESULTS}

The ability of oximes studied to reactivate tabun-inhibited AChE in vitro is characterized by kinetic parameters (Table 1) and shown in Fig. 1. While monopyridinium oxime pralidoxime was not able to reactivate tabun-inhibited $\mathrm{AChE}$ at all because the percentage of reactivation did not reach $5 \%$ regardless of pralidoxime concentration used, currently used bispyridinium oximes (obidoxime, the oxime HI-6) show certain potency to reactivate tabuninhibited $\mathrm{AChE}$ in vitro. Nevertheless, the reactivating efficacy of these oximes is low because the percentage of $\mathrm{AChE}$ reactivation does not reach $20 \%$ regardless of concentration of oximes. To compare obidoxime and the oxime HI-6, obidoxime seems to be better reactivator of tabun-inhibited AChE than HI-6 especially at $10^{-5}$ and $10^{-4} \mathrm{M}$ concentrations. Trimedoxime, another promising bispyridinium oxime, seems to be the most efficacious reactivator of tabun-inhibited $\mathrm{AChE}$, especially at higher concentrations, because it is able to reactivate in vitro more than $40 \%$ of tabun-inhibited $\mathrm{AChE}$ at $10^{-3} \mathrm{M}$ concentration (Fig. 1).

The ability of tested oximes to reactivate tabun-inhibited AChE in vitro shown as the values of percentage of reactivation generally corresponds to the values of dissociation constant of enzyme-reactivator complex $\left(K_{\mathrm{dis}}\right)$, dissociation constant of enzyme-inhibitor-reactivator complex $\left(K_{\mathrm{R}}\right)$ and first-order rate constant $\left(k_{\mathrm{R}}\right)$. The dissociation constants represent the affinity of oximes for intact and phosphorylated $\mathrm{AChE}$, the rate constant represents the velocity of reactivation of tabun-inhibited AChE (Table 1).

The ability of oximes to reactivate tabun-inhibited $\mathrm{AChE}$ in rat blood, diaphragm and brain in vivo is shown in Table 2. Trimedoxime seems to be the best reactivator of tabun-inhibited AChE among studied oximes $(p<0.05)$ because it was able to significantly reactivate tabun-in-
Table 3. $\mathrm{LD}_{50}$ values of oximes following i.m. administration in rats

\begin{tabular}{|l|c|}
\hline OXIME & $\mathrm{LD}_{50}(\mathrm{mg} / \mathrm{kg}) \pm 95 \%$ confidence limit \\
\hline Pralidoxime & $218.0(209.1-228.0)$ \\
\hline Obidoxime & $158.4(138.2-178.9)$ \\
\hline HI-6 & $781.3(738.4-826.6)$ \\
\hline Trimedoxime & $150.5(142.1-159.4)$ \\
\hline
\end{tabular}

Table 4. The prophylactic antidotal potency $\left(\mathrm{ED}_{50}\right.$ value $)$ and safety ratio (SR) of oximes in tabun-poisoned rats

\begin{tabular}{|l|c|c|}
\hline \multicolumn{1}{|c|}{ OXIME } & $\begin{array}{c}\mathrm{ED}_{50}(\mathrm{mg} / \mathrm{kg}) \pm 95 \% \\
\text { confidence limit }\end{array}$ & $\mathrm{SR}\left(\mathrm{LD}_{50} / \mathrm{ED}_{50}\right)$ \\
\hline Pralidoxime & $>150$ & $<1.45$ \\
\hline Obidoxime & $2.3(1.2-4.4)$ & 68.87 \\
\hline HI-6 & $158.9(73.3-344.5)$ & 4.92 \\
\hline Trimedoxime & $0.4(0.2-0.8)$ & 376.25 \\
\hline
\end{tabular}

Table 5. $\mathrm{LD}_{50}$ values of oximes following i.m. administration in mice

\begin{tabular}{|l|c|}
\hline OXIME & $\mathrm{LD}_{50}(\mathrm{mg} / \mathrm{kg}) \pm 95 \%$ confidence limit \\
\hline Pralidoxime & $263.6(253.7-273.8)$ \\
\hline Obidoxime & $188.4(156.3-208.0)$ \\
\hline HI-6 & $671.3(627.4-718.3)$ \\
\hline Trimedoxime & $149.3(124.1-184.5)$ \\
\hline
\end{tabular}


Table 6. The potency of oximes in combinatin with atropine to eliminace acute lethal effects of tabu $n$ in mice

\begin{tabular}{|l|c|c|}
\hline \multicolumn{1}{|c|}{ Treatment } & $\begin{array}{c}\mathrm{LD}_{50}(\mu \mathrm{g} / \mathrm{kg}) \pm 95 \% \\
\text { confidence limit }\end{array}$ & $\begin{array}{c}\text { Protective } \\
\text { ratio }\end{array}$ \\
\hline- & $295.9(275.5-317.9)$ & - \\
\hline $\begin{array}{l}\text { Pralidoxime }+ \\
\text { atropine }\end{array}$ & $329.3(313.3-346.2)$ & 1.11 \\
\hline $\begin{array}{l}\text { Obidoxime }+ \\
\text { atropine }\end{array}$ & $435.7(410.9-461.9)^{*}$ & 1.47 \\
\hline HI-6 + atropine & $485.3(460.4-511.5)^{*}$ & 1.64 \\
\hline $\begin{array}{l}\text { Trimedoxime }+ \\
\text { atropine }\end{array}$ & $506.0(470.3-545.1)^{*}$ & 1.71 \\
\hline
\end{tabular}

* Significantly different from non-treated group at the level of $\mathrm{p}<0.05$.

hibited AChE in peripheral as well as central compartment $(p<0.001)$ on the contrary of other studied oximes. Obidoxime was also able to significantly reactivate tabuninhibited AChE $(\mathrm{p}<0.001)$ in the peripheral compartment (blood and diaphragm) but not in the central compartment (brain). Other tested oximes (pralidoxime and the oxime HI-6) were practically ineffective to reactivate tabun-inhibited AChE regardless of the tissue with the exception of reactivation of tabun-inhibited AChE in diaphragm by pralidoxime $(\mathrm{p}<0.05)$.

These results closely correlate with the prophylactic antidotal potency of the oximes tested against lethal tabun poisoning in rats (Table 4). Trimedoxime and obidoxime are effective against tabun lethal poisoning of rats because they are able to protect rats at doses lower than those suggested for humans - less than $2 \%$ of their $\mathrm{LD}_{50}$ (Table 3). On the other hand, the oxime HI-6 is able to protect tabun-poisoned rats at doses that are significantly higher than those suggested for humans and pralidoxime is completely ineffective in protecting tabun-poisoned rats at therapeutic doses (Table 4).

To compare the therapeutical potency of studied oximes administered at 1 min after tabun poisoning in mice, trimedoxime seems to be the most efficacious oxime in the elimination of tabun-induced acute toxic effects in mice (Table 6), although the differences between the therapeutic efficacy of bispyridiniium oximes tested are not so high as in the case of their prophylactic efficacy studied in rats. Especially, the therapeutic potency of the oxime HI6 is not significantly lower compared to obidoxime and trimedoxime. This fact is caused by higher dose of HI-6 compared to other oximes studied due to its significantly lower toxicity in mice (Table 5).

\section{DISCUSSION}

The values of kinetic parameters of tested oximes for the reactivation of tabun-inhibited AChE in vitro show that dissociation constants and rate constant are lower compared to the kinetic parameters describing the reactivation of sarin, soman or cyclosin-inhibited AChE by the same oximes ${ }^{15-17}$. Therefore, all tested oximes should be generally considered to be relatively weak reactivators of tabun-inhibited $\mathrm{AChE}$ in vitro although there are significant differences among them. The differences in the chemical structure of the oximes (the number of pyridinium rings, the bridge between pyridinium rings, the number and position of oxime groups) have been shown to be important for the affinity of oximes for intact and phosphorylated $\mathrm{AChE}$ and for the potency and velocity of the reactivation of tabun-inhibited $\mathrm{AChE}^{18}$.

The relatively high reactivating efficacy of trimedoxime in vitro can be explained by the big difference between the affinity of trimedoxime to the intact and tabun-inhibited $\mathrm{AChE}$. This fact is advantageous because a possible inhibition of reactivated enzyme by the excess of trimedoxime is practically excluded and, in addition, the strength of binding of trimedoxime to inhibited $\mathrm{AChE}$ decreases the concentration of trimedoxime necessary to reactivate tabun- inhibited AChE. On the other hand, other currently used oximes (obidoxime and especially HI-6) show the low value of both dissociation constants and, therefore, the excess of these oximes can inhibit reactivated enzyme because the difference between the affinity of both oximes to the intact and tabun-inhibited AChE is small. In addition, the markedly higher value of the first-order rate constant of trimedoxime compared to other currently used oximes, especially pralidoxime and the oxime HI-6, declares the advantage for trimedoxime as the reactivator of tabun-inhibited $\mathrm{AChE}$ too ${ }^{18}$.

In vitro results correlate with the results obtained in vivo. Trimedoxime that is characterized by relatively high percentage of tabun-inhibited AChE in vitro was demonstrated to be the most efficacious reactivator of tabun-inhibited AChE in vivo and sufficiently efficacious to protect rats poisoned with lethal dose of tabun. On the other hand, pralidoxime and the oxime HI-6 that seem to be poor tabun-inhibited $\mathrm{AChE}$ in vitro are not able to sufficiently reactivate tabun-inhibited $\mathrm{AChE}$ in vivo nor protect rats poisoned with supralethal doses of tabun when they are administered at human relevant doses. Obidoxime is almost as effective as trimedoxime to reactivate tabuninhibited $\mathrm{AChE}$ and to protect rats poisoned with lethal doses of tabun with the exception of the reactivation of tabun-inhibited AChE in the brain. The fact that oximes are able to penetrate across the blood-brain barrier and reactivate nerve agent-inhibited $\mathrm{AChE}$ in the brain despite their quaternary structure was previously described by various researchers ${ }^{19,20}$. The significant difference between the reactivating efficacy of trimedoxime and obidoxime in the central compartment can be explained by the difference of the structure of the bridge between pyridinium rings. The bridge involved in obidoxime increases the ionization of obidoxime molecule as it is demonstrated by lower values of $\mathrm{pK}_{\mathrm{a}}$ compared to trimedoxime and, thus, decreases the potency of obidoxime to penetrate across blood-brain barrier compared to trimedoxime ${ }^{21}$. 
It is necessary to mention that the therapeutical efficacy of all oximes studied decreases when they are administered following tabun poisoning. Therefore, none of oximes studied was able to protect mice poisoned with tabun at a supralethal dose corresponding to $2 \times \mathrm{LD}_{50}$ when they were administered 1 min after tabun poisoning. The therapeutic efficacy of all oximes is also influenced by their toxicity in mammals. The low efficacy of the oxime HI-6 is partly compensated by its low toxicity for mammals and by its possibility to be administered at significantly higher dose compared to other bispyridinium oximes $^{5}$.

Our results confirm that there is no single, broad-spectrum oxime suitable for the antidotal treatment of poisonings with all organophosphorus agents ${ }^{5}$. While obidoxime is preferred for the treatment of acute poisoning with organophosphorus insecticides (OPI) because it is considered to be the best reactivator of OPI-inhibited AChE, the oxime HI-6 appears to be very promising antidote against some highly toxic fluorophosphonates, especially soman, because it is able to protect experimental animals from toxic effects and improve survival of animals poisoned with fluorophosphonates ${ }^{5}$. Nevertheless, our results clearly demonstrate its low potency to reactivate tabun-inhibited $\mathrm{AChE}$. On the other hand, trimedoxime, relatively weak reactivator of soman-inhibited $\mathrm{AChE}$, is the most promising reactivator of tabun-inhibited $\mathrm{AChE}$ according to our data. Thus, trimedoxime should be considered to replace currently used oximes in the treatment of acute tabun poisonings. In addition, our results show that the evaluation of the oxime reactivating efficacy in vitro closely correlates with their ability to reactivate tabun-inhibited AChE in vivo and to eliminate tabun-induced lethal toxic effects in the case of experimental poisonings.

\section{ACKNOWLEDGEMENT}

The authors wish to thank to Mrs Martina Hrabinová and Mrs Jana Uhlírová for their skilful assistance and to Mr Václav Bláha for the statistical data evaluation. The study was supported by the grant of Ministry of Defence, No OBVLAJEP20032.

\section{REFERENCES}

1. Marrs TC. (1993) Organophosphate poisoning. Pharmacol Ther $58,51-66$

2. Cabal J, Bajgar J. (1999) Tabun - reappearance 50 years later. Chem Listy 93, 27-31 (in Czech).
3. Jokanovic M, Maksimovic M, Kilibarda V, Jovanovic D, Savic D. (1996) Oxime-induced reactivation of acetylcholinesterase inhibited by phosphoramidates. Toxicol Lett $85,35-9$.

4. Bajgar J. (2004) Organophosphates/nerve agents poisoning: mechanism of action, diagnosis, prophylaxis, and treatment. Adv Clin Chem 38, 151-216.

5. Kassa J. (2002) Review of oximes in the antidotal treatment of poisoning by organophosphorus nerve agents. J Toxicol - Clin Toxicol 40, 803-16.

6. Rousseaux CG, Dua AK. (1989) Pharmacology of HI-6, an H series oxime. Can J Physiol Pharmacol 67, 1183-89.

7. Kassa J. (1995) Comparison of two oximes (HI-6 and obidoxime) in soman poisoning in rats. Toxicology 101, 167-74.

8. Clement JG, Shiloff JD, Gennings C. (1987) Efficacy of a combination of acetylcholinesterase reactivators, HI-6 and obidoxime, against tabun and soman poisoning in mice. Arch Toxicol 61, 70-5.

9. Worek F, Widmann R, Knopff O, Szinicz L. (1998) Reactivating potency of obidoxime, pralidoxime, HI-6 and HLö-7 in human erythrocyte acetylcholinesterase inhibited by highly toxic organophosphorus compounds. Arch Toxicol 72, 237-43.

10. Kuča K, Kassa J. (2003) A comparison of the ability of a new bispyridinium oxime - 1-(4-hydroxyiminomethylpyridinium)-4-(4carbamoylpyridinium) butane dibromide and currently used oximes to reactivate nerve agent-inhibited rat brain acetylcholinesterase by in vitro methods. J Enzyme Inhib Med Chem 18, 529-35.

11. Wang EIC, Braid PE. (1967) Oxime reactivation of diethylphosphoryl human serum cholinesterase. J Biol Chem 242, 2683-6.

12. Clement JG, Hansen AS, Boulet CA. (1992) Efficacy of HLö-7 and pyrimidoxime as antidotes of nerve agent poisoning in mice. Arch Toxicol 66, 216-9.

13. Ellman GL, Courtney DK, Andres VJr, Feartherstone RM. (1961) A new and rapid colorimetric determination of acetylcholinesterase activity. Biochem Pharmacol 7, 88-93.

14. Tallarida R, Murray R. Manual of Pharmacological Calculation with Computer Programs. New York: Springer, 1987.

15. Kassa J, Cabal J. (1999) A comparison of the efficacy of a new asymmetric bispyridinium oxime BI-6 with currently available oximes and $\mathrm{H}$ oximes against soman by in vitro and in vivo methods. Toxicology 132, 111-8.

16. Kassa J, Cabal J. (1999) A comparison of the efficacy of a new asymmetric bispyridinium oxime BI-6 with presently used oximes and $\mathrm{H}$ oximes against sarin by in vitro and in vivo methods. Hum Exp Toxicol 18, 560-5.

17. Kassa J, Cabal J. (1999) A comparison of the efficacy of acetylcholinesterase reactivators against cyclohexylmethylphosphonofluoridate (GF agent) by in vitro and in vivo methods. Pharmacol Toxicol 84, 41-5.

18. Cabal J, Kuča K, Kassa J. (2004) Specification of the structure of oximes able to reactivated tabun-inhibited acetylcholinesterase. Basic Clin Pharmacol Toxicol 95, 81-6.

19. Clement JG. (1992) Central activity of acetylcholinesterase oxime reactivators. Toxicol Appl Pharmacol 112, 104-9.

20. Sakurada K, Matsubara K, Shimizu K, Shiono H, Seto Y, Tsuge K, Yoshino M, Sakai I, Mukoyama H, Takatori T. (2003) Pralidoxime iodide (2-PAM) penetrates across the blood brain barrier. Neurochem Res 28, 1401-7.

21. Terrier F, MacCormack P, Kizilian E, Hallé J-C, Demerseman P, Guir F, Lion C. (1991) Non-linear bronsted correlations: evidence for a levelling off in the reactivity of oximate ions in aqueous solution. J Chem PerkinTrans 2, 153-8. 